\title{
PAPER
}

\section{Neurogenic fever after traumatic brain injury: an epidemiological study}

\author{
H J Thompson, J Pinto-Martin, M R Bullock
}

J Neurol Neurosurg Psychiatry 2003;74:614-619

\begin{abstract}
Objectives: To determine the incidence of neurogenic fever (NF) in a population of patients in the acute phase following severe traumatic brain injury (TBI); to identify factors associated with the development of NF following severe TBI in adults. Methods: Charts of patients admitted from 1996 to 1999 with severe TBI at a large, urban mid-Atlantic teaching hospital were retrospectively evaluated based on diagnostic criteria for each episode of hyperthermia to determine the diagnosis of NF. Data were collected regarding mechanism and area of injury, severity of injury, and demographic factors to determine potential predictors of NF. Results: Diffuse axonal injury (DAI) (OR 9.06, 95\% Cl 0.99 to 82.7 ) and frontal lobe injury of any type (OR $6.68,95 \% \mathrm{Cl} 1.1$ to 39.3) are independently predictive of an increased risk of development of NF following severe TBI. The presence of a skull fracture and lower initial Glasgow Coma Score (GCS) were individual predictors of development of NF, but did not contribute to the final model.

Conclusions: These findings examine known and novel risk factors for this phenomenon in comparison to previously published literature on NF. A set of predictor variables was identified to help clinicians target patients at high risk for development of NF following severe TBI. It is hoped that earlier diagnosis and appropriate intervention for fever in the TBI patient will lead to improved outcomes.
\end{abstract}

See end of article for authors' affiliations

Correspondence to: H J Thompson, 105C Hayden Hall, 3320 Smith Walk, Dept of Neurosurgery, University of Pennsylvania, Philadelphia, PA 19104, USA; hilairet@nursing.upenn.edu

Received 20 July 2002

Accepted

7 January 2003

$\mathrm{P}$ atients with TBI frequently experience febrile episodes that may be of infectious or non-infectious origins. Neurogenic fever is a non-infectious source of fever in the patient with TBI. Until recently, NF was thought to be a relatively rare consequence of TBI, but other studies have reported that $4-37 \%$ of TBI survivors experience this sequela..$^{1-4}$ Neurogenic fever results from a disruption in the hypothalamic set point temperature which results in an abnormal increase in body temperature and is thought to be caused by injury to the hypothalamus. ${ }^{256}$ TBI results in many different types of injury, and at this point it is unclear if one particular type is associated with an increased incidence of NF. From cadaveric studies it is known, however, that hypothalamic injury is common in patients after TBI as $42.5 \%$ of the brains prosected had evidence of hypothalamic injury. ${ }^{7}$ No data are presently available to describe the incidence of hypothalamic injury in survivors of TBI.

Most reports characterise the patient with NF as being relatively bradycardic, having a notable absence of perspiration, having a plateau-like temperature curve (no diurnal variation) that persists for days to weeks, the temperature being characteristically very high, and resistant to antipyretic medications. ${ }^{24-68}$ These criteria were utilised in aiding in the diagnosis of NF during data collection. Neurogenic fever may be associated with the presence of prolonged unawareness or coma state and diabetes insipidus. ${ }^{49}$

Currently NF is a diagnosis of exclusion and the diagnostic work up of the TBI patient with fever must be exhaustive before the diagnosis can be made. ${ }^{2-11}$ This often leads to expensive, invasive, and often painful tests in order to make the diagnosis. ${ }^{11}{ }^{12}$ As a result of the lengthy diagnostic period for NF, the start of rehabilitation is often delayed as the patient is viewed as medically unstable and this delay may impact the patient's ultimate functional recovery. ${ }^{11}$

The neurologic effects of fever are significant as increased temperature in the post-injury period has been associated with increased local cytokine activity, increased infarct size, and poorer outcomes in the acute phase of injury. ${ }^{13-17}$ This is, in part, related to the fact that patients at risk of intracranial hypertension may be significantly affected by rises in temperature because the intracranial blood volume increases with temperature. This reduces compliance and puts the brain at risk for further injury. ${ }^{6}$ Hyperthermia, from fever or other sources, when high enough $\left(>43^{\circ} \mathrm{C}\right)$, has been reported to cause neuronal injury in normal brain, and lengthy periods of moderate $\left(40^{\circ} \mathrm{C}\right)$ hyperthermia have been reported to alter brain structure and functioning. ${ }^{13} 18$ Dietrich and colleagues examined the central nervous system effects of hyperthermia following both global cerebral ischaemia and fluid percussion TBI in rodent models, reporting that hyperthermia significantly increased mortality and cellular damage. ${ }^{14} 19$

Additionally, the TBI patient is at risk of secondary injury from fever as for every $1^{\circ} \mathrm{C}$ rise in body temperature, there is a $13 \%$ increase in the metabolic rate. ${ }^{20}$ This taxes the stressed energy reserves of the severely brain injured, catabolic patient. The higher metabolic demand of fever exacerbates this problem, and can lead to additional loss of muscle and fat stores.

The treatment of NF includes use of external cooling methods until the diagnosis is made and appropriate drug therapy may be started. Many drugs have successfully been used either anecdotally or in case reports to treat NF including: bromocriptine, amantadine, dantrolene, and propranolol. ${ }^{12}$ As each of these drugs has significant potential side effects (for example, hypotension, gastrointestinal bleeding), routine use without a relatively firm diagnosis of NF is not prudent. Thus, the development of a predictive model to aid in the diagnosis of NF would be a valuable addition to the current state of the science. The purposes of this study were to determine the

Abbreviations: $C T$, computed tomography; DAl, diffuse axonal injury; GCS, Glasgow Coma Score; HP, hypothalamic-pituitary; ISS, Injury Severity Score; MRI, magnetic resonance imaging; NF, neurogenic fever; $\mathrm{TBI}$, traumatic brain injury 


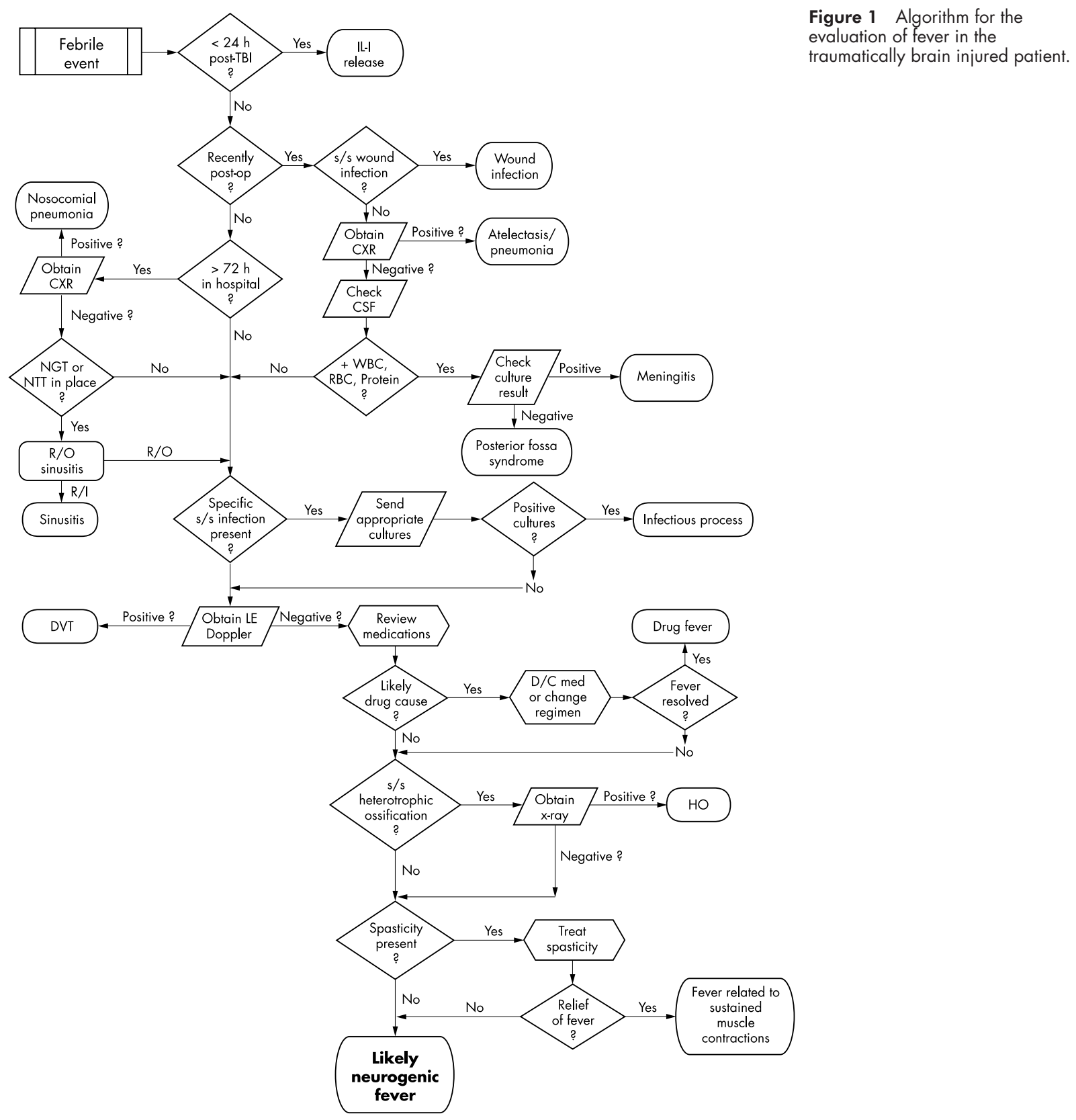

incidence in the acute phase of injury and to identify factors associated with the development of NF following severe TBI in adults.

\section{METHODS}

\section{Design}

A retrospective analysis of chart data was used for this exploratory study. Subjects for this study were patients diagnosed with NF identified from the head injury databank for years 1996-99 at the Medical College of Virginia Hospital/ Virginia Commonwealth Health System. The comparison group was patients with a diagnosis of severe TBI without a diagnosis of NF. For each patient, the entire chart was reviewed for episodes of hyperthermia/fever and for each episode of hyperthermia, a determination of aetiology was made. The diagnosis of NF was made based on reviewing available patient data following the diagnostic algorithm (fig 1).

\section{Sampling criteria}

The potential sample consisted of adult patients with severe TBI admitted to a large, urban, teaching hospital located in the
mid-Atlantic area, designated as a level I trauma centre for years 1996-99. Exempted Institutional Review Board approval was obtained prior to study initiation.

Inclusion criteria for both cases and controls in this study were: (1) patient who required hospitalisation for an admitting diagnosis of severe TBI who was alive at least two weeks after initial injury; and (2) patient must be over 18 years of age. According to the limited data available, TBI patients experience NF more frequently than patients with other neurological deficits such as non-traumatic subarachnoid haemorrhage, and are more vulnerable to the metabolic consequences of fever. ${ }^{3}$ Neurogenic fever generally does not develop in the hyperacute phase of TBI, thus the two week survival criteria.

Exclusion criteria included patients with a history of malignant hyperthermia as they have an altered baseline thermoregulatory mechanism. Of the 167 patients admitted in 1996-99 with severe TBI, 87 patients met criteria; full medical records were not available on all of the remaining subjects, thus the final enrolment was 76 (see table 1 for summary of excluded patients). 


\begin{tabular}{|ll|}
\hline $\begin{array}{l}\text { Table } 1 \text { Summary of excluded } \\
\text { patients }\end{array}$ \\
\hline Reason excluded & $\mathrm{n}$ \\
\hline Expired & 47 \\
Under age 18 & 14 \\
Hospitalised less than 2 weeks & 19 \\
Total number of excluded patients & 80 \\
\hline
\end{tabular}

\section{Instrumentation}

The mechanism of injury was collected from the chart, and checked for congruence with the trauma registry and head computed tomography (CT) and/or magnetic resonance imaging (MRI) films. The presence of hyperthermia in the six hours immediately following the TBI as a predictor for development of NF was determined by chart review of vital sign recordings. Hyperthermia is defined to be a temperature of $1^{\circ} \mathrm{C}$ or more above patient baseline if normothermic at time of initial assessment, or any temperature of $38.5^{\circ} \mathrm{C}$ or above. The presence of hypothalamic-pituitary (HP) dysfunction was determined by chart review for the diagnosis of diabetes insipidus, evidence of abnormal prolactin secretion, or secretion of inappropriate antidiuretic hormone during the hyperacute phase of care.

Initial head injury severity was measured by the GCS. ${ }^{21}$ Injury severity was measured by the Injury Severity Score (ISS). ${ }^{22}$ The ISS is the sum of the squares of the most severe injury in each of the three most severely injured body regions. The six body regions on which the ISS is based are head/neck, face, chest, abdomen/pelvic contents, extremities/pelvic girdle, and external. The ISS is scored on a scale of 1 (least severe) to 75 (most severe). ${ }^{22}$

\section{Data collection procedures}

Once access to the dataset was obtained via exempted Institutional Review Board approval, the head injury registry was reviewed for patients meeting inclusion criteria for the years 1996-99. The identified subject's medical record was reviewed to confirm the presence/absence of NF utilising a diagnostic algorithm (see fig l) and the subject was allocated to either the case or control group. For this study, identification of a case was made on the presence of a diagnosis of NF. The diagnosis of NF is one of exclusion and is based on a multitude of tests and assessment data including negative culture results, ruling out other possible sources of fever in the patient (see fig 1), and the presence of previously discussed clinical symptoms such as relative bradycardia and lack of diurnal variation. ${ }^{5}$ As data collection was retrospective, not all patients had all testing required to definitively confirm NF per the algorithm; therefore, any uncertainty in the classification of cases and controls was resolved by discussion with a second clinician. The medical record was reviewed for demographic data (including age, sex, and race) to ensure the sample was representative of the TBI population. Temperature recordings in the patient's medical record for the first six hours after injury were reviewed for the presence of hyperthermia and hypothermia as potential predictive factors for later development of NF. The subject's pertinent head CT and MRI scans and reports were reviewed for type of injury. If necessary, confirmation of radiological findings were sought from a neuroradiologist. Injury severity scores were culled from the trauma registry at the institution.

\section{Statistical analysis}

This case-comparison study utilises logistic regression analysis to answer the research questions of interest. All data management and descriptive and inferential statistical analyses
Table 2 Demographic and clinical characteristics of 76 patients with severe traumatic brain injury admitted between 1996 and 1999

\begin{tabular}{|c|c|}
\hline Variable & Data \\
\hline Mean age (SD) & $35.4(14.0)$ \\
\hline Men/women, $\mathrm{n}$ & $64 / 12$ \\
\hline \multicolumn{2}{|l|}{ Race $(\%)$} \\
\hline White, non-Hispanic & 54 \\
\hline Black & 37 \\
\hline Hispanic & 3 \\
\hline Other & 6 \\
\hline Median Glasgow Coma score on admit (range) & $6(3-14)$ \\
\hline Mean Injury Severity score (SEM) & $27.1(10.7)$ \\
\hline Mean length of stay (SD) & $43.3(52.2)$ \\
\hline Hyperthermic in first 6 hours (\%) & 68.4 \\
\hline Hypothermic in first 6 hours (\%) & 39.5 \\
\hline \multicolumn{2}{|l|}{ Type of brain injury (\% yes) } \\
\hline Subdural haematoma & 56.6 \\
\hline Epidural haematoma & 18.4 \\
\hline Subarachnoid haemorrhage & 39.5 \\
\hline Contusion & 63.2 \\
\hline Laceration & 2.6 \\
\hline Diffuse axonal injury & 7.9 \\
\hline Skull fracture & 35.5 \\
\hline \multicolumn{2}{|l|}{ Side of primary injury involved (\%) } \\
\hline Left only & 35.3 \\
\hline Right only & 23.5 \\
\hline Bilateral & 41.2 \\
\hline \multicolumn{2}{|l|}{ Area of brain injured (\% yes) } \\
\hline Frontal & 52.6 \\
\hline Temporal & 59.2 \\
\hline Parietal & 42.1 \\
\hline Occipital & 15.8 \\
\hline Cerebellum & 7.9 \\
\hline Brain stem & 6.6 \\
\hline Evidence of HP pathology; $n,(\%)$ & $11(14.5)$ \\
\hline
\end{tabular}

were performed using the SPSS 8.0 statistical software package. Initial GCS on admission was classified into one of four levels based on head injury severity: 3-4 (most severe), 5-8 (severe), 9-12 (moderate), and above 13 (mild). The most severe category was used as the referent group in the comparative analysis.

\section{RESULTS}

From 1996 to 1999,76 patients with severe TBI were available for study. Table 2 presents demographics on the patient population. The incidence of NF in this population was $11.8 \%$ (9/76). Each of the variables was tested independently for association with development of NF following severe traumatic brain injury using univariate logistic regression (results are presented in table 3$)$. The set of factors that exhibited a significant $(p<0.05)$ or relatively significant $(p=0.10)$ association with development of NF remained in the model (GCS, diffuse axonal injury, frontal injury, skull fracture). Both backward and forward Wald model building was used to arrive at the final set of predictor variables (table 4). Of the four patient attributes tested, only two entered the logistic regression model as independent predictors of development of NF following severe TBI. These predictors in order of relative prognostic strength are presence of diffuse axonal injury and frontal lobe injury of any type.

\section{Diffuse axonal injury}

Patients with diffuse axonal injury (DAI) present on imaging studies were 9.1 ( $95 \%$ CI 0.99 to 82.7 ) times more likely to develop NF than TBI patients without DAI, all other factors being equal. 
Table 3 Univariate NF development results for severely brain injured patients

\begin{tabular}{lll}
\hline Variable & Univariate p value & Multivariate p value \\
\hline Age & 0.3307 & \\
Sex & 0.7103 & \\
Race & 0.3518 & 0.0924 \\
Glasgow Coma score & $0.0412^{*}$ & \\
Injury Severity score & 0.3061 & \\
Temperature within 6 hours after injury & & \\
Hyperthermic after injury & 0.6151 & \\
Hypothermic after injury & 0.9418 & \\
HPA axis pathology & 0.5359 & \\
Side of injury & 0.1524 & \\
Type of injury & & \\
Subdural haematoma & 0.8868 & \\
Epidural haematoma & 0.4874 & 0.0508 \\
Subarachnoid haemorrhage & 0.6885 & 0.2323 \\
Contusion & 0.8996 & \\
Laceration & 0.5847 & 0.0355 \\
Diffuse axonal injury & $0.0568^{*}$ & \\
Skull fracture & $0.0751^{*}$ & \\
Area injured & & \\
Frontal & $0.0499^{*}$ & \\
Temporal & 0.2729 & \\
Parietal & 0.8566 & \\
Occipital & 0.1515 & \\
Cerebellum & 0.1070 & \\
Brain stem & 0.5991 & \\
\hline * Sigifirn & &
\end{tabular}

*Significant at $p<0.05$

Table 4 Summary of Wald logistic regression analysis for variables predicting risk of development of neurogenic fever following severe traumatic brain injury $(n=76)$

\begin{tabular}{|c|c|c|c|c|c|}
\hline Variable & $\begin{array}{l}\text { Regression } \\
\text { coefficient }\end{array}$ & SE & $\mathrm{p}$ value & Odds ratio (OR) & $95 \% \mathrm{Cl}$ for OR \\
\hline Diffuse axonal injury & 2.2038 & 1.129 & 0.0508 & 9.0592 & 0.9921 to 82.7234 \\
\hline Frontal lobe injury & 1.8998 & 0.9037 & 0.0355 & 6.6843 & 1.1371 to 39.2936 \\
\hline
\end{tabular}

\section{Frontal lobe injuries}

Patients with frontal lobe injuries were at a statistically significantly increased risk for development of NF in comparison to those without frontal lobe involvement, being 6.7 (95\% CI l.1 to 39.3) times more likely to develop this sequela of TBI.

This model has good overall correct predictive value (92.0\%). Diffuse axonal injury entered into the model despite having a significance value of $p=0.0508$. Removal of DAI from the model resulted in a poorer predictive model. Thus, the best predictive model is presented (table 4), and was confirmed with regression modelling.

\section{Attributes not independently predictive}

Glasgow Coma Score, as a measure of severity of brain injury, individually predicted the development of NF, but did not contribute to the model after adjustment for the above factors. The severely injured patients with GCS scores on admission of 5-8 were at a statistically significantly increased risk $(p=0.0339)$ for development of NF in comparison to the referent group. This was likely due to the fact that the majority of subjects $(n=48)$ fell into this category, thus distribution was not equal throughout. Once adjustment was made for other factors in the overall model, this attribute fell out as a significant independent predictor. Skull fracture was also individually predictive of NF development subsequent to severe TBI, but did not contribute to the overall final model.

\section{DISCUSSION}

In this retrospective study, there is an increased risk of development of NF among patients with severe TBI who had experienced either DAI or frontal lobe injury of any form. These data are novel in attempting to establish a relation between injury factors and later development of this sequela in survivors of TBI. Additionally, this is thought to be the first study to examine this complication following TBI in a group of acutely injured adults. Limitations of this study include its retrospective nature, the small number of identified cases, and the exclusion of TBI patients less than 18 years of age (related to exempted review requirements).

Approximately $20000-45000$ patients suffer significant physical or functional deficits as a result of TBI induced DAI in the United States each year, and it is the most common cause of persistent vegetative state in TBI patients. ${ }^{23}$ Thus, as previous studies in comatose patients following $\mathrm{TBI}^{424}$ have found an association between NF and persistent vegetative state, it is not surprising that this study found DAI to be an independent predictor of NF development. Severe DAI is associated with lower GCS scores with midbrain and brain stem injury, ${ }^{23}$ and would be a likely mechanism of hypothalamic injury following TBI as the thermoregulatory tracts of the hypothalamus are deep brain structures.

In the original study design, an attempt was made to determine the presence of hypothalamic injury from imaging studies, as no information in surviving patients has been published to date and would likely have been quite useful in this analysis. Determining the presence of hypothalamic injury proved to be extremely difficult based on available studies. Because of the retrospective nature of the study, a decision was made to cease collecting this information following consultation with a radiologist as CT scans of the head for evaluation of traumatic injury generally do not include the precision within the diencephalon required to make this determination. 
Table 5 Comparison of data based publications regarding development of neurogenic fever

\begin{tabular}{|c|c|c|c|}
\hline Study & Subjects/number & Findings & Comments \\
\hline Benedek et $a^{26}$ & $\begin{array}{l}\text { Mixed population: } \\
\text { Cranial trauma }(n=6) \text { and brain } \\
\text { surgery }(n=5)\end{array}$ & $\begin{array}{l}\text { Central medial forebrain involved in all cases. } \\
\text { Indomethacin reduced fever in } 10 / 11 \text { patients }\end{array}$ & $\begin{array}{l}\text { First } 24 \text { hours post-injury. Likely } \\
\text { secondary fever from IL-1 release, not } \\
\text { neurogenic fever }\end{array}$ \\
\hline Meythaler and Stinson' & Severe TBI $(n=3)$ & $\begin{array}{l}\text { Initial GCS } \leqslant 4 \text {, prolonged coma in all cases. } \\
\text { Intraventricular haemorrhage present in } 2 / 3 \text { cases }\end{array}$ & $\begin{array}{l}\text { Case reports. Propranolol was used } \\
\text { successfully for treatment }\end{array}$ \\
\hline Whyte et al ${ }^{11}$ & Severe TBI patient $(n=1)$ & $\begin{array}{l}\text { Patient with known NF in acute post-injury phase } \\
\text { had chronic thermoregulatory deficits } 3 \text { years } \\
\text { post-injury. Basilar skull fracture, brain stem injury, } \\
\text { prolonged coma }\end{array}$ & Case report \\
\hline Childers et $a^{2}$ & $\begin{array}{l}\text { TBI patients admitted to } \\
\text { rehabiliation unit within } 45 \text { days of } \\
\text { injury }(n=84)\end{array}$ & Incidence: $4 \%$ in this population & $\begin{array}{l}\text { Retrospective study focused on } \\
\text { incidence. Used algorithmic approach } \\
\text { to determine presence of NF }\end{array}$ \\
\hline Clinchot et $a^{\beta}$ & $\begin{array}{l}\text { Mixed brain injured population } \\
(n=286) \text { on rehabilitation unit, TBI } \\
(n=226)\end{array}$ & $\begin{array}{l}\text { Unexplained fever occurred in } 7 \% \text { of } \mathrm{TBI} \text { patients } \\
\text { during rehabilitation stay }\end{array}$ & $\begin{array}{l}\text { Retrospective study focused on } \\
\text { incidence of fever and determining } \\
\text { aetiology }\end{array}$ \\
\hline $\begin{array}{l}\text { Sazbon and } \\
\text { Grosswasser }\end{array}$ & $\begin{array}{l}\text { TBI patients in prolonged coma }(>1 \\
\text { month) }(n=134)\end{array}$ & $\begin{array}{l}\text { Presence of NF within first week following injury } \\
\text { was significant for predicting non-recovery }\end{array}$ & Retrospective study \\
\hline Heindl and Laub ${ }^{24}$ & $\begin{array}{l}\text { Mixed population of children: } \\
\text { TBI }(n=82) \text { and hypoxic brain injury } \\
(n=45)\end{array}$ & $\begin{array}{l}\text { Neurogenic fever in patients with TBI was } \\
\text { correlated with lower Barthel Index scores at } 19 \\
\text { month follow up }\end{array}$ & Retrospective enrolment \\
\hline Thompson et al & TBI patients $(n=76)$ & $\begin{array}{l}\text { DAl and frontal lobe injury are independently } \\
\text { predictive, skull fracture and lower GCS are } \\
\text { individually predictive of development of NF }\end{array}$ & $\begin{array}{l}\text { Retrospective study. Developed } \\
\text { predictive model }\end{array}$ \\
\hline
\end{tabular}

Prospective studies should include provision of analysis of the hypothalamus for damage in the design whenever possible.

Injury to the frontal lobe was an independent predictor for development of NF. As the frontal lobe contains no major thermoregulatory centres, it is possible that frontal lobe injury serves as an indication of hypothalamic injury in this study given the nature of mechanical forces within the skull during injury and the proximity of the hypothalamus to the ventricles. Skull fracture was also an individual predictor of $\mathrm{NF}$, but was not an independent predictor for development of NF. Skull fracture has previously been associated with other indicators of hypothalamic injury following TBI such as diabetes insipidus. ${ }^{25}$ No information was collected on the individual site(s) of skull fracture in this study. It would be important in future studies to determine if location of the fracture in proximity to the hypothalamic region (for example, anterior fossa) may increase this risk. Evidence of HP pathology, such as diabetes insipidus or syndrome of inappropriate secretion of antidiuretic hormone, was not an individual predictor of NF despite previously published reports suggesting an association. ${ }^{9}$ This finding may have been related to the relatively low number $(n=11)$ of TBI patients exhibiting HP pathology in this study as well as a function of the small number of cases seen. Table 5 presents a summary comparing this study's findings with work to date.

Fever in the severely injured TBI patient is a commonly encountered diagnostic and management problem. ${ }^{27}{ }^{28}$ Rapid control of the hyperthermia associated with fever in the TBI patient is essential as it is associated with worsened outcome in both experimental and clinical studies. ${ }^{14} 1929$ Sources of fever in this population are numerous, and diagnosis often made more difficult as patients cannot communicate their symptoms to the clinician. Differentiating a patient with a NF from a patient who is has true infectious or inflammatory source to the fever is a critical diagnostic decision for the clinician caring for the TBI patient to make. The two treatment regimens differ significantly; thus rapid and proper diagnosis and treatment is essential for control of fever and optimisation of patient outcome following TBI.
It was not possible to strictly follow the algorithm in determining the presence of NF, as not all tests were performed on each patient in the study because of the retrospective nature of the data collection. In these cases, any uncertainty in the classification of cases and controls was resolved by discussion with a second clinician. This process generated discussion between investigators regarding the most appropriate history, physical examination, and diagnostic work up for NF. As the diagnosis of NF is currently a diagnosis of exclusion, additional information that may help the clinician in more rapidly identifying the ultimate source of hyperthermia may be a valuable diagnostic aid. While the algorithm presented in fig 1 should remain the standard for diagnostic work up of NF, not every patient will fit an algorithm, nor is it always feasible to strictly follow one.

\section{Conclusions}

These findings suggest that clinicians working up patients with severe TBI who are experiencing unexplained fever need to additionally consider the presence of two presenting factors: DAI and frontal injury in their assessment. If the patient experienced either factor, the clinician's suspicion for the diagnosis of NF should be increased as these data suggest that the patient's risk is significantly elevated by their presence. It is hoped that earlier diagnosis and appropriate intervention in this patient population will lead to improved outcomes. These initial findings are intriguing; however, due to the small sample size they should be interpreted with prudence. Further work in this area is needed with additional patients and sites, prospective data analysis for confirmation of findings, and specification of site of skull fracture.

\section{ACKNOWLEDGEMENTS}

This study was supported by United States Public Heath Service Grant NR. 7694 and the Neuroscience Nursing Foundation. We thank Charlotte Gilman, RN of the Neurosurgery Division for her assistance with the head injury databank, and the Trauma Registry of the Medical College of Virginia Hospitals, Richmond, VA. 


\section{Authors' affiliations}

H J Thompson, School of Nursing, and Department of Neurosurgery, The University of Pennsylvania, Philadelphia, PA, USA

J Pinto-Martin, School of Nursing, The University of Pennsylvania

M R Bullock, Division of Neurosurgery, Virginia Commonwealth University Health System, VA, USA

Competing interests: None declared

\section{REFERENCES}

1 Meythaler JM, Stinson AM. Fever of central origin in traumatic brain injury controlled with propranalol. Arch Phys Med Rehabil 1994;75:816-18.

2 Childers MK, Rupright J, Smith DW. Post-traumatic hyperthermia in acute brain injury rehabilitation. Brain Inj 1994;8:335-43

3 Clinchot DM, Otis S, Colachis SC. Incidence of fever in the rehabilitation phase following brain injury. Am J Phys Med Rehabil 1997;76:323-7.

4 Sazbon L, Groswasser Z. Outcome in 134 patients with prolonged posttraumatic unawareness. J Neurosurg 1990;72:75-80.

5 Cunha BA, Tu RP. Fever in the neurosurgical patient. Heart Lung 1988;17:608-11.

6 Segatore $M$. Fever after traumatic brain injury. J Neurosci Nurs 1992;24:104-9.

7 Crompton MR. Hypothalamic lesions following closed head injury. Brain 1971;94:165-72.

8 Powers JH, Scheld WM. Fever in neurologic diseases. Infect Dis Clin North Am 1996;10:45-66.

9 Lausberg G. Significance of thermoregulatory disorders in the multi-injured with predominantly cranial lesion. Cahiers d'Anesthesiologie $1971 ; 19: 315-24$.

10 Cunha BA, Digamon-Beltran M, Gobba PN. Implications of fever in the critical care setting. Heart Lung 1984;13:460-5.

11 Whyte J, Filion DT, Rose TR. Defective thermoregulation after traumatic brain injury: a single subject evaluation. Am J Phys Med Rehabil 1993;72:281-5.

12 Thompson HJ. Evaluation of fever in the traumatically brain-injured patient: etiology and treatment [abstract]. In: Proceedings of the 29th Annual Meeting of the American Association of Neuroscience Nurses. Chicago: AANN, 1997:10.

13 Dietrich WD. The importance of brain temperature in cerebral injury. J Neurotrauma 1992;9:S475-85.
14 Dietrich WD, Alonso O, Halley $M$, et al. Delayed post-traumatic brain hyperthermia worsens outcome after fluid percussion brain injury: a light and electron microscopic study in rats. Neurosurgery 1996;38:533-41.

15 Chatzipanteli K, Alonso OF, Kraydieh S, et al. Importance of posttraumatic hypothermia and hyperthermia on the inflammatory response after fluid percussion brain injury: biochemical and immunocytochemical studies. J Cereb Blood Flow Metab 2000;20:531-42.

16 Kakuda W, Naritomi H, Shimizu T, et al. Body temperature increases following embolic stroke correlating with size of infarction. J Cereb Blood Flow Metabolism 1997;17(suppl 1):S43.

17 Kuroiwa T, Bonnekoh P, Hossmann KA. Prevention of postischemic hyperthermia prevents ischemic injury of $\mathrm{CA} 1$ neurons in gerbils. J Cereb Blood Flow Metab 1990;10:550-6.

18 Britt RH, Lyons BE, Pounds DW, et al. Feasibility of ultrasound hyperthermia in the treatment of malignant brain tumors. Medical Instrumentation 1983;17:172-7.

19 Dietrich WD, Busto R, Valdes I, et al. Effects of normothermic versus mild hyperthermic forebrain ischemia in rats. Stroke 1990;21:1318-25.

20 Holtzclaw $B$. The febrile response in critical care: state of the science. Heart Lung 1992;21:482-500.

21 Teasdale G, Jennett $B$. Assessment of coma and impaired consciousness: a practical scale. Lancet 1974;2:81-4.

22 Baker SP, O'Neill B, Haddon W Jr. The injury severity score: a method for describing patients with multiple injuries and evaluating care. J Trauma 1974;14:187-96.

23 Meythaler JM, Peduzzi JD, Eleftheriou E, et al. Current concepts: diffuse axonal injury-associated traumatic brain injury. Arch Phys Med Rehabil 2001;82:1461-71

24 Heindl UT, Laub MC. Outcome of persistent vegetative state following hypoxic or traumatic brain injury in children and adolescents. Neuropediatrics 1996;27:94-100.

25 Kern KB, Meislin HW. Diabetes insipidus: occurrence after mild head trauma. J Trauma 1984;24:69-72.

26 Benedek G, Toth-Daru P, Janaky J, et al. Indomethacin is effective against neurogenic hyperthermia following cranial trauma or brain surgery. Can J Neurol Sci 1987:14:145-8.

27 Albrecht RF, Wass C, Lanier WL. Occurrence of potentially detrimental temperature alterations in hospitalized patients at risk for brain injury. Mayo Clin Proc 1998;73:629-35.

28 Kilpatrick MM, Lowry DW, Firlik AD, et al. Hyperthermia in the neurosurgical intensive care unit. Neurosurgery 2000;47:850-6.

29 Soukup J, Zauner A, Doppenberg EMR, et al. The importance of brain temperature in patients after severe head injury: relationship to intracranial pressure, cerebral perfusion pressure, cerebral blood flow, and outcome. J Neurotrauma 2002;19:559-71. 